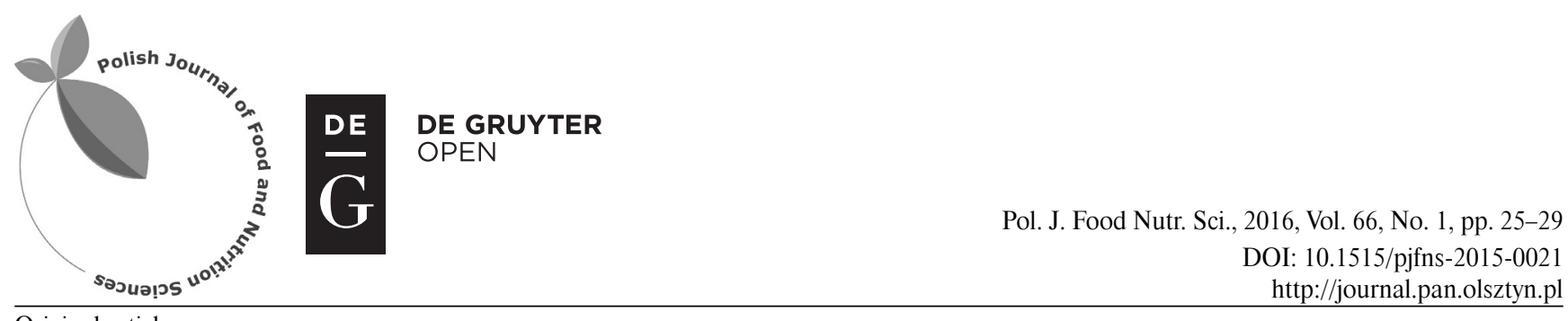

Original article

Section: Food Technology

\title{
Research on Pork Jerky Obtained Through Fermentation with Pediococcus acidilactici
}

\author{
Xingxiu Zhao, Jing Zhang, Hongmei Ming, Wei Zou, Yang Wang, \\ Changqing Zhao*, Shengdong Mu, Hao Zhang, Lin Qiu \\ College of Bioengineering, Sichuan University of Science and Engineering, Number 180, \\ Xueyuan Street, Huixing Road, Zigong, Sichuan, 643000, P. R. China
}

Key words: pork jerky, fermentation, Pediococcus acidilactici

Pediococcus acidilactici was used to ferment fresh pork. After fermentation, the pork jerky was subjected to sensory evaluation and the levels of $\mathrm{pH}$, free amino acids, and volatile compounds were measured. The results showed that the fermented pork jerky had a better sensory evaluation score (score: 93.2), lower $\mathrm{pH}$ value (3.54), and more free amino acids $(39.24 \mathrm{mg} / 100 \mathrm{~g}$ ). Furthermore, in the fermented pork jerky, the content of three acids $(18.552 \%)$ was high, which lowered the $\mathrm{pH}$ of the pork jerky and inhibited growth of pathogens. Moreover, some new compounds produced, including 3-hydroxy-2-butanone (49.095\%), 2,3-butanediol (2.790\%), 2-ethyl-1-hexanol $(2.400 \%)$, oxalic acid isobutyl hexyl ester (2.280\%), phenylethyl alcohol $(0.953 \%)$, and eucalyptol $(0.659 \%)$, contributed to the flavour of pork jerky. Overall, our results demonstrated that P. acidilactici can be used for the production as well as improvement of the quality and flavour of fermented pork jerky.

\section{INTRODUCTION}

Traditional pork jerky, which is a special product of China, is usually produced in Sichuan, Guizhou, Zhejiang through being cooked with many kinds of spiceries and then baked. It is usually hard in texture and poor in colour because of the dehydration of meat during the cooking and baking process [Konieczny et al., 2007]. Substances, including nitrite, aginomoto, and preservative, which are harmful to human health, are used to improve the colour and extend the shelf life of pork jerky [Sun \& Ma, 2004]. It has been reported that the texture, colour, and flavour of the prepared pork jerky could be improved through fermentation with lactobacillus; in addition, the stability and safety of pork jerky could also be enhanced by the comprehensive effects of microbial metabolites during the fermentation process without the addition of nitrite, aginomoto, or preservative [Li \& LV, 2005].

In recent years, there have been some reports on fermenting raw pork to fermented meat products, including dry sausage [Visessanguan et al., 2006], semi-dry sausage [Porto-Fett et al., 2008], salami [Tian et al., 2012; Porto-Fett et al., 2010], ham [Zhu et al., 2014], and soongchimchae [Cho et al., 2011]. However, to the best of our knowledge, there have been no studies on the fermentation of raw pork to pork jerky.

In general, fermented jerky is evaluated using parameters such as sensory evaluation, $\mathrm{pH}$, and contents of free amino acids and flavour compounds [Wang et al., 2010]. In the present study,

\footnotetext{
* Corresponding Author: Tel.: +86 813 5505979; Fax: +86 813 5505872;

E-mail: zhaocq81@126.com (Changqing Zhao)
}

pork was fermented with Pediococcus acidilactici and the parameters, including sensory evaluation, $\mathrm{pH}$, and contents of free amino acids and flavour compounds were evaluated.

\section{MATERIALS AND METHODS}

\section{Materials}

Biochemical-grade yeast extract and peptone were purchased from Beijing Aoboxing Biotech. Co. Ltd. (Beijing, China) and Chengdu Changshou Biotech. Co. Ltd (China), respectively. All other reagents, including glucose, lactose, sodium chloride, and ninhydrin, used in this study were of research grade.

\section{P. acidilactici}

The lactobacillus P. acidilactici, preserved in our laboratory which was effective for the fermentation of pork jerky through our previous experiments, was used in the experiments. Prior to use, the organism was cultured in liquid enlargement medium containing beef extract, $2.5 \mathrm{~g}$; peptone, $5 \mathrm{~g}$; yeast extract, $2.5 \mathrm{~g}$; glucose, $5 \mathrm{~g}$; lactose, $2.5 \mathrm{~g} ; \mathrm{NaCl}, 2.5 \mathrm{~g}$; and water, $500 \mathrm{~mL}$, with a pH of 6.8 [Li, 2012].

\section{Preparation of pork jerky meat}

\section{Pretreatment of pork}

Raw pork tenderloin was purchased and immersed in cold water for $1 \mathrm{~h}$. Subsequently, the pork was precooked for $10 \mathrm{~min}$ and turned over to ensure uniform heating, and cooled after sieving. Then, the pork was sliced using a kitchen knife to an approximate size of $3 \mathrm{~cm} \times 4 \mathrm{~cm} \times 0.5 \mathrm{~cm}$. 
Fermentation of pork

A total of $5 \%(\mathrm{~V} / \mathrm{V})$ of the enlargement medium cultured P. acidilactici (initial concentration of $10^{7} \times \mathrm{CFU} / \mathrm{mL}$ ) was inoculated into the liquid enlargement medium. After incubation at $35^{\circ} \mathrm{C}$ for $24 \mathrm{~h}$ at $100 \mathrm{rpm}$, which was favourable for $P$. acidilactici growth and fermentation, the fermentation broth was obtained.

Subsequently, $25 \mathrm{~g}$ of the pretreated pork slices were added to a sterilised beaker containing $50 \mathrm{~mL}$ of the fermentation broth at a $\mathrm{pH}$ of 5.5. After sealing with a plastic wrap, the beakers were cultured at $35^{\circ} \mathrm{C}$ for $58 \mathrm{~h}$ for the fermentation of pork jerky. In addition, the inoculated fermentation broth cultured under the same condition was used as the control.

\section{Cooking and baking of pork}

After removing from the fermentation broth, the fermented meat was boiled for $10 \mathrm{~min}$ to end the fermentation process and gently agitated during cooking for uniform ripening of the pork. The samples were considered ready after baking at $50^{\circ} \mathrm{C}$ for $120 \mathrm{~min}$ and subsequent cooling. The pork meat precooked, cooked, and baked, but not fermented, was used as the control and named as fresh pork.

\section{Determination of the properties of pork jerky}

\section{Sensory evaluation}

A trained panel consisting of eight people evaluated some of the sensory properties of the fermented pork jerky and fresh pork, including flavour, mouth feel, texture, and colour. The panel scored the samples according to the evaluation standard [Wang et al., 2010].

\section{Determination of the $\mathrm{pH}$ value}

The $\mathrm{pH}$ values were evaluated for fresh pork, pork jerky, and inoculation medium before and after fermentation using a pH meter (pHS-3C, Chengdu Fangzhou Technology Experiment Equipment Co., China). A total of $1 \mathrm{~g}$ of the solid samples was ground in a mortar, soaked in $10 \mathrm{~mL}$ of distilled water for $30 \mathrm{~min}$, and filtered.

\section{Determination of the content of free amino acids}

The free amino acid contents of the samples, including fresh pork, pork jerky, and inoculation medium before and after fermentation, were determined using the colorimetric method of ninhydrin [Zhang, 2005]. Accordingly, ninhydrin was added to the samples under acidic conditions and the absorbance of the solution was ascertained at $570 \mathrm{~nm}$.

\section{Determination of the content of volatile compounds}

\section{Headspace solid-phase microextraction}

A headspace solid-phase microextraction (HS-SPME) holder (Supelco Inc., Shanghai, China) for manual sampling, combined with gas chromatography-mass spectrometry (GC-MS) (Agilent Technologies, USA), was used to perform the experiments. Teflon covers and a $75-\mu \mathrm{m}$ carboxen/ polydimethylsiloxane fibre were purchased from Supelco Inc. Before initial use, the fibre was preconditioned for $2 \mathrm{~h}$ on an Agilent 6890-5975 gas chromatograph at an injector tem- perature of $230^{\circ} \mathrm{C}$. Then, the minced samples of fresh pork and pork jerky $(3 \mathrm{~g})$ were respectively placed in a $15-\mathrm{mL}$ vial at room temperature, and the vial was sealed with a Teflon cover, heated at $60^{\circ} \mathrm{C}$ in a water bath for $30 \mathrm{~min}$, and mixed at intervals. The HS-SPME fibre was inserted for sampling for $40 \mathrm{~min}$, which was adequate to extract the volatile compounds from the samples and introduce them into the GC-MS injector for desorption for $5 \mathrm{~min}$.

\section{GC-MS analysis}

The GC-MS analysis was performed on an Agilent 6890 gas chromatograph coupled with a 5975 mass spectrometer (Agilent Technologies, USA). The carrier gas was helium with a flow rate of $1.1 \mathrm{~mL} / \mathrm{min}$. The separation was performed on a DB-WAX $30 \mathrm{~m} \times 0.25 \mathrm{~mm} \times 0.25 \mu \mathrm{m}$ capillary column (Agilent Technologies, USA). The initial oven temperature was $35^{\circ} \mathrm{C}$ for $1 \mathrm{~min}$, which was ramped to $100^{\circ} \mathrm{C}$ at the rate of $8^{\circ} \mathrm{C} / \mathrm{min}$ and held for $3 \mathrm{~min}$; subsequently, the temperature was ramped to $120^{\circ} \mathrm{C}$ at the rate of $3^{\circ} \mathrm{C} / \mathrm{min}$ and held for $2 \mathrm{~min}$; finally, the temperature was ramped to $230^{\circ} \mathrm{C}$ at the rate of $5^{\circ} \mathrm{C} / \mathrm{min}$ and held for $5 \mathrm{~min}$. The mass detector was operated at $230^{\circ} \mathrm{C}$ in an electron impact mode at $70 \mathrm{eV}$. The ion-source temperature was $230^{\circ} \mathrm{C}$, while the transfer line temperature was $150^{\circ} \mathrm{C}$. The chromatograms were recorded by monitoring the total ion currents in the 20 -350 mass range.

\section{Data analysis}

The data obtained were analysed using MSD Productivity ChemStation Data Analysis Software (version G1701DA). Identification of volatile compounds was confirmed by comparing their mass spectra with those in the National Institute for Standards and Technology (NIST, Search Version 2.0) and Pesticides Retention Time Lock (RTLPEST, Parts number G1672AA, version A.03.00) mass spectral library. Determination of the percentage composition was based on peak area normalisation (expressing the area of a given peak as a percentage of the sum of the areas of all the peaks) without the use of correction factors.

\section{RESULTS AND DISCUSSION}

\section{Sensory evaluation of the fermented pork jerky}

According to the evaluation standard [Wang et al., 2010], the trained panel consisting of eight people scored the flavour (total score of 60), mouth feel (total score of 20), texture (total score of 10), and colour (total score of 10) of the samples. As shown in Table 1, the sensory evaluation score (including flavour, mouth feel, texture, and colour) of the fermented pork jerky was 93.2, which was obviously better than that of the fresh pork (which was not fermented; score: 83.0), indicating that the flavour, mouth feel, texture, and colour of the pork jerky were improved after fermentation.

\section{pH of the pork jerky}

As shown in Figure 1, the $\mathrm{pH}$ values of both pork jerky and inoculation medium decreased after fermentation. The $\mathrm{pH}$ of the pork jerky was 3.54, which was distinctly lower than that of fresh pork (pH: 6.42), because P. acidilactici has 
TABLE 1. Sensory properties of fermented pork jerky and fresh pork.

\begin{tabular}{|c|c|c|c|c|}
\hline \multirow{2}{*}{ Sensory properties } & \multicolumn{2}{|l|}{ Pork jerky } & \multicolumn{2}{|l|}{ Fresh pork } \\
\hline & Description & Score & Description & Score \\
\hline $\begin{array}{l}\text { Flavour } \\
\text { (total score of 60) }\end{array}$ & $\begin{array}{l}\text { Had strong flavour of meat } \\
\text { and unique flavour of sauce }\end{array}$ & 56.0 & $\begin{array}{c}\text { Had flavour of sauce } \\
\text { and strong flavour of meat }\end{array}$ & 52.3 \\
\hline $\begin{array}{l}\text { Mouth feel } \\
\text { (total score of 20) }\end{array}$ & Chewable, soft, and did not stick to teeth & 19.0 & $\begin{array}{l}\text { Did not stick to teeth, but was } \\
\text { not very easy to chew }\end{array}$ & 16.1 \\
\hline $\begin{array}{l}\text { Texture } \\
\text { (total score of } 10)\end{array}$ & $\begin{array}{l}\text { Some muscle fibres fractured; } \\
\text { the structure was a little } \\
\text { loose, but formed }\end{array}$ & 9.2 & $\begin{array}{l}\text { Muscle fibres were complete; } \\
\text { the structure was compacted and formed }\end{array}$ & 6.1 \\
\hline $\begin{array}{l}\text { Colour } \\
\text { (total score of } 10 \text { ) }\end{array}$ & Uniform colour of red sauce & 8.8 & Regular colour of red sauce & 7.5 \\
\hline Total score & & 93.2 & & 83.0 \\
\hline
\end{tabular}

Note: According to the evaluation standard [Wang et al., 2010], the trained panel consisting of eight people scored the flavour (total score of 60), mouth feel (total score of 20), texture (total score of 10), and colour (total score of 10) of the samples.

TABLE 2. Content of free amino acids in the pork samples and inoculation medium before and after fermentation.

\begin{tabular}{c|c|c|c|c}
\hline & Pork jerky & Fresh pork & $\begin{array}{c}\text { Medium after } \\
\text { fermentation }\end{array}$ & $\begin{array}{c}\text { Medium before } \\
\text { fermentation }\end{array}$ \\
\hline Content of free amino acids & $39.24 \mathrm{mg} / 100 \mathrm{~g}$ & $25.27 \mathrm{mg} / 100 \mathrm{~g}$ & $22.30 \mathrm{mg} / \mathrm{mL}$ & $2.74 \mathrm{mg} / \mathrm{mL}$ \\
\hline
\end{tabular}

Note: The free amino acid contents of the samples were determined using the colorimetric method of ninhydrin [Zhang, 2005]. Accordingly, ninhydrin was added to the samples under acidic conditions and the absorbance of the solution was ascertained at $570 \mathrm{~nm}$.

a strong ability to produce various acids during fermentation. As a result of the low $\mathrm{pH}$ of pork jerky, the growth of pathogens such as Listeria spp., Staphylococcus aureus, etc. could be inhibited, making the samples safer and preserving them for a longer duration.

\section{Free amino acid content before and after fermentation}

The content of free amino acids (which can be easily assimilated by humans) is an important parameter for the evaluation of the nutritional value of pork [Chen \& Liu, 2004]. As can be seen from Table 2, the content of free amino acids in pork jerky fermented with $P$. acidilactici was $39.24 \mathrm{mg} / 100 \mathrm{~g}$, exhibiting an increase of $13.97 \mathrm{mg} / 100 \mathrm{~g}$, which was more than half of that noted in fresh pork $(25.27 \mathrm{mg} / 100 \mathrm{~g})$. This increase in the free amino acid content was due to the degradation of many proteins in pork to free amino acids by protease produced by $P$. acidilactici during fermentation, as noted in our previous experiments.

\section{Volatile compound content in pork jerky}

The volatile compound contents in fresh pork and pork jerky are shown in Table 3. As shown in Table 3, a total of 15 kinds of volatile compounds, including acids, alcohols, aldehydes, esters, alkanes, ketones, and benzene ring compounds, were identified in the fresh pork and fermented pork jerky samples. However, the number of species of volatile compounds was not very high because the samples were thoroughly cooked and baked, resulting in the volatilization of some of these compounds.

A total of six and twelve volatile compounds were found in fresh pork and pork jerky, respectively, whereas two volatile compounds, namely, butanoic acid (No. 3) and benzaldehyde (No. 17), were observed in both fresh pork and pork jerky. The compounds detected only in fresh pork were 1-pentanol (No. 6) and hexanal (No. 16). Among them, the total con- tent of hexanal (No. 16), which was generated by the oxidation of lipids, reached the highest percentage of $63.578 \%$. In general, hexanal is considered to have a fragrance odour of grass and apple, with the characteristic odour of oils [Chen \& Jiang, 2009]. It disappeared in the pork jerky which might be because that the hexanal was transformed to other compounds with the mechanism of the Pediococcus acidilactici.

Some new compounds, including three acids, four alcohols, one ester, one alkane, one ketone, and one benzene ring compound, were produced during the fermentation of pork jerky. Among them, the three acids, including acetic acid (No. 1), propanoic acid (No. 2), and octanoic acid (No. 4), with a total content of $18.552 \%$, lowered the $\mathrm{pH}$ of the pork jerky, thus inhibiting the growth of pathogens. The alcohols produced were 3-methyl-1-butanol (No. 5), which is obtained from leucine; 2-ethyl-1-hexanol (No. 7) $(2.400 \%)$, which has been detected as a flavour compound in fermented foods such as Jinhua ham [Zhao, 2013]; 2,3-butanediol (No. 8-12; 2.79\%), which is a kind of chiral compound usually added to spirit to improve flavour and might react with acetic acid to produce 1,3-butane-

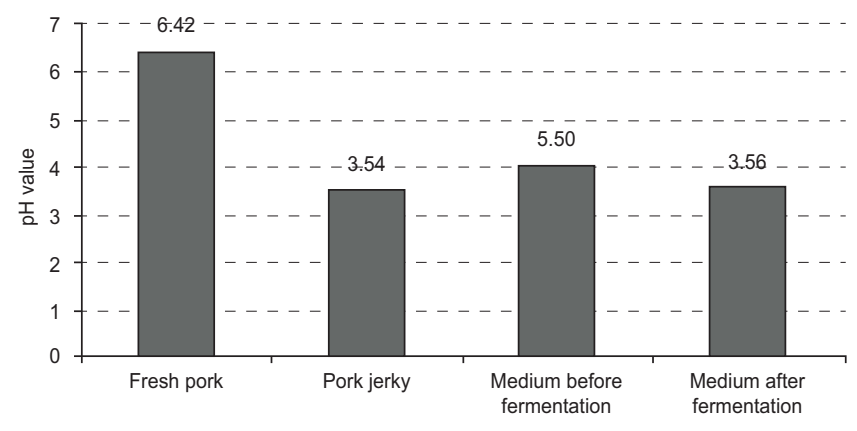

FIGURE 1. The $\mathrm{pH}$ of pork samples and inoculation medium before and after fermentation. 
TABLE 3. Volatile compound content in fresh pork and pork jerky.

\begin{tabular}{|c|c|c|c|c|}
\hline No. & Volatile compounds & $\begin{array}{c}\text { Retention } \\
\text { time }\end{array}$ & $\begin{array}{l}\text { Fresh } \\
\text { pork }\end{array}$ & $\begin{array}{l}\text { Pork } \\
\text { jerky }\end{array}$ \\
\hline \multicolumn{5}{|c|}{ Acids } \\
\hline 1 & Acetic acid & 19.827 & & $8.671 \%$ \\
\hline 2 & Propanoic acid & 23.557 & & $8.788 \%$ \\
\hline 3 & Butanoic acid & 26.944 & $2.912 \%$ & $1.447 \%$ \\
\hline 4 & Octanoic acid & 33.23 & & $1.193 \%$ \\
\hline \multicolumn{5}{|c|}{ Alcohols } \\
\hline 5 & 3-Methyl-1-butanol & 10.314 & & $4.056 \%$ \\
\hline 6 & 1-Pentanol & 13.418 & $1.135 \%$ & \\
\hline 7 & 2-Ethyl-1-hexanol & 21.617 & & $2.400 \%$ \\
\hline 8 & $\begin{array}{l}\text { 2,3-Butanediol, } \\
{\left[\mathrm{R}-\left(\mathrm{R}^{*}, \mathrm{R}^{*}\right)\right]-}\end{array}$ & 23.981 & & $0.275 \%$ \\
\hline 9 & $\begin{array}{c}\text { 2,3-Butanediol, } \\
\left.\text { [R-(R* }\left(\mathrm{R}^{*}, \mathrm{R}^{*}\right)\right]-\end{array}$ & 24.333 & & $1.443 \%$ \\
\hline 10 & 2,3-Butanediol & 24.41 & & $0.261 \%$ \\
\hline 11 & $\begin{array}{l}\text { 2,3-Butanediol, } \\
{\left[\mathrm{R}-\left(\mathrm{R}^{*}, \mathrm{R}^{*}\right)\right]-}\end{array}$ & 25.446 & & $0.672 \%$ \\
\hline 12 & $\begin{array}{c}\text { 2,3-Butanediol, } \\
\left.\text { [R-(R*, }\left(\mathrm{R}^{*}\right)\right]-\end{array}$ & 25.496 & & $0.142 \%$ \\
\hline 13 & Phenylethyl alcohol & 34.877 & & $0.953 \%$ \\
\hline \multicolumn{5}{|c|}{ Ester } \\
\hline 14 & $\begin{array}{l}\text { Oxalic acid isobutyl } \\
\text { hexyl ester }\end{array}$ & 7.273 & & $2.280 \%$ \\
\hline \multicolumn{5}{|c|}{$\begin{array}{r}\text { Alkane } \\
\end{array}$} \\
\hline 15 & Eucalyptol & 9.421 & & $0.659 \%$ \\
\hline \multicolumn{5}{|c|}{ Aldehydes } \\
\hline 16 & Hexanal & 9.248 & $63.578 \%$ & \\
\hline 17 & Benzaldehyde & 23.05 & $0.782 \%$ & $3.270 \%$ \\
\hline \multicolumn{5}{|c|}{ Ketone } \\
\hline 18 & 3-Hydroxy-2-butanone & 13.454 & & $49.095 \%$ \\
\hline \multicolumn{5}{|c|}{ Benzene ring compounds } \\
\hline 19 & 1,3-Dimethyl benzene & 5.995 & & $1.731 \%$ \\
\hline
\end{tabular}

dioldiacetate, improving the flavour of cream [Zhao, 2008]; and phenylethyl alcohol (No. 13), which has a weaker pleasant sweet rose-like fragrance and might be degraded to aldehyde by phenylalanine and subsequently reduced to phenylethyl alcohol [Zhao \& Ding, 2001]. Ester is a wellknown flavour contributor to fermented foods, and only one kind of ester (oxalic acid isobutyl hexyl ester; No. $14 ; 2.280 \%$ ) was detected in the fermented pork jerky, because the esters in fermented pork jerky were volatilized after baking. With regard to alkanes, due to their higher threshold value, their contribution to the overall flavour of pork jerky was not significant. However, some branched-chain alkanes, such as 2,4,10,14-tetramethyl-pentadecane and 2,6,10,14-tetramethyl-pentadecane, have been reported to have a pleasant flavour [Benincasa et al., 2003]. Among the detected alkanes, eucalyptol (No. 15) had branched-chain structures, and is usually used as a toothpaste perfume and therefore might contribute to the flavour of pork jerky. With respect to ketone, 3-hydroxy-2-butanone (No. 18) was not detected in fresh pork, but was found in fermented pork jerky $(49.095 \%)$, contributing to the flavour of pork jerky. This ketone naturally exists in butter, cocoa, wine, and strawberry and has a pleasant aroma of milk when highly diluted and a strong butter, fat, and butter-like flavour.

The GC-MS analysis revealed that three acids, namely, acetic acid (No. 1), propanoic acid (No. 2), and octanoic acid (No. 4), were found in high contents $(18.552 \%)$ in pork jerky, which lowered the $\mathrm{pH}$ value of pork jerky, thus inhibiting the growth of pathogens. Furthermore, other new compounds, which were only detected in pork jerky, including 3-hydroxy-2-butanone (No. 18; 49.095\%), 2,3-butanediol (No. 8-12; 2.790\%), 2-ethyl-1-hexanol (No. 7; 2.400\%), oxalic acid isobutyl hexyl ester (No. 14; $2.280 \%$ ), phenylethyl alcohol (No. 13; 0.953\%), and eucalyptol (No. 15; 0.659\%), contributed to the flavour of pork jerky.

\section{CONCLUSION}

The results of the present study showed that $P$. acidilactici could effectively ferment fresh pork to pork jerky. Fermentation of pork jerky produced more nutritious free amino acids and three acids, namely, acetic acid, propanoic acid, and octanoic acid, which lowered the $\mathrm{pH}$ of pork jerky, thus inhibiting the growth of pathogens. Furthermore, some new compounds produced, including 3-hydroxy-2-butanone, 2,3-butanediol, oxalic acid isobutyl hexyl ester, phenylethyl alcohol, and eucalyptol, contributed to the flavour of pork jerky. In conclusion, the fermentation method described in the present study can be used for the production of pork jerky with improved quality and flavour.

\section{ACKNOWLEDGEMENTS}

This work was financially supported by Sichuan University of Science \& Engineering (Item No. 2012RC10), the Science and Technology Bureau of Zigong city (Item No. 2013N13), the Department of Education of Sichuan Province (Item No. 201410622011) and the Key Laboratory of Sichuan Meat Processing (Item No. 15-R02).

\section{REFERENCES}

1. Benincasa C., DeNino A., Lombardo N., Assay of aroma active components of virgin olive oils from southern Italian regions by SPME-GC/Ion Trap Mass Spectrometry. J. Agric. Food Chem., 2003, 51, 733-741.

2. Chen G.S., Liu M.Y., Analysis of nutritional characteristics of wild crossbred pig muscle. Swine Prod., 2004, 1, 24-27 (in Chinese; English abstract).

3. Chen S.S., Jiang G.D., Volatile flavor components in meat of chinese mitten crab (Eriocheir sinensis). Food Sci., 2009, 30(20), 308-311 (in Chinese; English abstract).

4. Cho G.Y., Lee M.H., Choi C., Survival of Escherichia coli O157:H7 and Listeria monocytogenes during kimchi fermentation supplemented with raw pork meat. Food Contr., 2011, 22, 1253-1260.

5. Konieczny P., Stangierski J., Kijowski J., Physical and chemical characteristics and acceptability of home style beef jerky. Meat Sci., 2007, 76, 253-257. 
6. Li C.T., LV J.L., Development of lactic acid bacteria and fermented dairy products. China Brewing, 2005, 8, 5-7 (in Chinese; English abstract).

7. Li F., Improvement of lactic acid bacteria starter's producing conditions and the influence to the cheese making. 2012, Harbin: Master Dissertation for Harbin Institute of Technology (in Chinese; English abstract).

8. Porto-Fett A.C.S., Call J.E., Hill D.E., Evaluation of fermentation, drying, and/or high pressure processing on viability of Listeria monocytogenes, Escherichia coli O157:H7, Salmonella spp., and Trichinella spiralis in raw pork and Genoa salami. Int. J. Food Microbiol., 2010, 140, 61-75.

9. Porto-Fett A.C.S., Hwang C.A., Call J.E., Viability of multistrain mixtures of Listeria monocytogenes, Salmonella typhimurium, or Escherichia coli O157:H7 inoculated into the batter or onto the surface of a soudjouk-style fermented semi-dry sausage. Food Microbiol., 2008, 25, 793-801.

10. Sun B.H., Ma L.Z., Science and Technology of Meat. 2004, Beijing: China Light Industry Press (in Chinese).

11. Tian H.Y., Zou H., Li J.P., Effects of fermentation conditions and additives on myoglobin forms during simulated fermentation of pork salami. Meat Res., 2012, 26, 1-5 (in Chinese; English abstract).
12. Visessanguan W., Benjakul S., Riebroy S., Changes in lipid composition and fatty acid profile of Nham, a Thai fermented pork sausage, during fermentation. Food Chem., 2006, 94, 580-588.

13. Wang Z.J., Huang J.R., Zhang Q., Study on processing technology of dried galangal-flavored meat dice. Meat Ind., 2010, 6, 20-23 (in Chinese; English abstract).

14. Zhang S.H., Food Analysis. 2005, Beijing: China Light Industry Press, (in Chinese).

15. Zhao D.Y., Ding X.L., Studies on the flavor components of pickled potherb mustard. Food Mach., 2001, 2, 22-24 (in Chinese; English abstract).

16. Zhao L.J., Study of FAA participated in Maillard reaction during flavor formation of Jinhua ham. 2013, Henan (China): Master Dissertation for Henan Agricultural University (in Chinese; English abstract).

17. Zhao S.M., Production of 2,3-Butanediol by fermentation. 2008, Jiangsu (China): Master Dissertation for Jiangnan University (in Chinese; English abstract).

18. Zhu C.Z., Zhang W.G., Kang Z.L., Stability of an antioxidant peptide extracted from Jinhua ham. Meat Sci., 2014, 96, 783-789.

Submitted: 19 August 2014. Revised: 15 December and 18 December 2014. Accepted: 13 February 2015. Published on-line: 29 June 2015. 
